\title{
Towards realizing best-in-class civil aviation strategy scenarios
}

\section{$\underline{\text { Abstract }}$}

The growth of the aviation industry and the increase in international competitiveness require proper policy orientation to ensure systematic, sustainable and orderly development of the national civil aviation sector. Hence, it is imperative that a clearly defined, long term civil aviation policy is formulated. What's more important for the aviation policy is to be based on national priorities. In the developed world, aviation strategic planning is a state-level activity used to provide guidelines for all aviation stakeholders and direct collective efforts towards common national goals. However, in the less developed world the opposite is generally the case. Practice shows that an organized and properly justified approach to development and management of the civil aviation system is normally lacking. Additionally, there exists no predefined framework to guide developing countries in formulating civil aviation strategies matching their macro-environment and competitiveness levels while addressing their future vision for growth or sustainability. Instead, civil aviation planning over-look these priorities and is often dictated by local political pressures, and mostly influenced by uncoordinated foreign aid assistance. Hence, developing countries use dissimilar and un-structured approaches to reach what is known as "civil aviation master plan" or "draft civil aviation policy". Recognizing that a problem exists in the mechanism for civil aviation planning in this part of the world, research is encouraged to highlight this substantial topic. This paper uses a scenario-based approach to study the roles played by the macro-environment and industry-level performance in realizing best-fit national civil aviation strategies. The goals are achieved through utilizing a performance benchmarking technique named Data Envelopment Analysis (DEA), on country level data on a sample of 52 countries in different stages of development. Results of the best performing countries - in terms of output efficiency, indicate that the maturity level of a country's macroenvironment and air transport sector's performance serve as guidelines to identify best-in-class civil aviation strategy scenarios. The output-efficient performing strategies are classified based on industry's standard and recommended practices and development trends in the aviation system. Such industry benchmarks assist governments in setting an appropriate vision for the future of civil aviation and establish an approach to direct and prioritize investment in the civil aviation sector. 
KEYWORDS: civil aviation strategy, scenario analysis, performance benchmarking.

\section{INTRODUCTION}

Aviation is considered as one of the most complex industries, not just from a technological, but also from a managerial point of view. Today's aviation managers are facing tough managerial and strategic challenges. Within the structure of the industry, the Department of Civil Aviation (DCA) commonly referred to as the Civil Aviation Authority (CAA) is the government agency entrusted with the promotion and development of air transport sector in the country. However, the range of roles and responsibilities of the CAA varies from one country to another due to variations in the context where the aviation agency exists. In some countries the CAA's role goes far beyond implementing and following up policies established by the ministry responsible for air transport. The CAA objective in this case is not only a regulatory one, but also more global in nature through planning and ensuring the development of the civil aviation activities in accordance with the public interest, economical, social developments and national security and safety objectives. Whereas in other countries, the department of civil aviation takes a dual role by acting as both a regulator and a provider of aerodrome and navigation services. The DCA's overlapping and in many cases conflicting functions may weaken its performance in pursing the set objectives for the development of the country's air transport sector. That is because the department is handling simultaneously regulatory and operational responsibilities.

In most developing nations the civil aviation infrastructure and operation is completely under the control of government, whose financial resources are often insufficient to maintain, upgrade or develop the airports, air traffic control or communications systems. Consequently, reliance is placed on outside funding, with the result that much of the investment that occurs comes by way of international technical assistance programmes, development bank loans, and increasingly from private sector sources. The effectiveness of investment in civil aviation infrastructure in countries reliant on foreign aid needs sometimes to be measured, specifically in developing countries with no clear national priorities, and no transparent mechanism to direct funds to those areas most in need. Instead, it is the priorities of the funding agencies that would seem to govern decisions as to where aviation system investments are made, and for what purpose. These 
decisions may not necessarily reflect the priorities and needs of the national government regarding civil aviation upgrading (LEAPP, 2001) ${ }^{1}$.

At the national level the civil aviation strategy should therefore set the roadmap for the development of civil aviation over a defined time period, including its administration, regulation, operations, infrastructure and financing. As such, it is the guiding policy, or master plan, for civil aviation in a nation, which must shape and accommodate the development of safe, secure and efficient air transport services, and ensure that suitable infrastructure is developed and maintained to support air transport.

The aviation strategic plan is not to be isolated from its context. To be effective as a guide to civil aviation investment, and to reflect national interests and priorities, aviation strategic planning must be part of a national policy planning process for transportation, along with policy directed towards development of other transport sectors such as railway, road transport, marine and ports. Transport Policy, along with other national policies directed towards social development, education, industry, defence, foreign affairs, trade, natural resource management and agriculture make up broader national policy. This is the only way to ensure that the civil aviation strategic plan can stand as a tool to implement national policy in the civil aviation sector, and be coordinated with the priorities of government towards other social or industrial sectors that may need to be supported by civil aviation, such as tourism and trade, for example (Figure 1). 
Figure 1: Air transport policy integration with other national policies

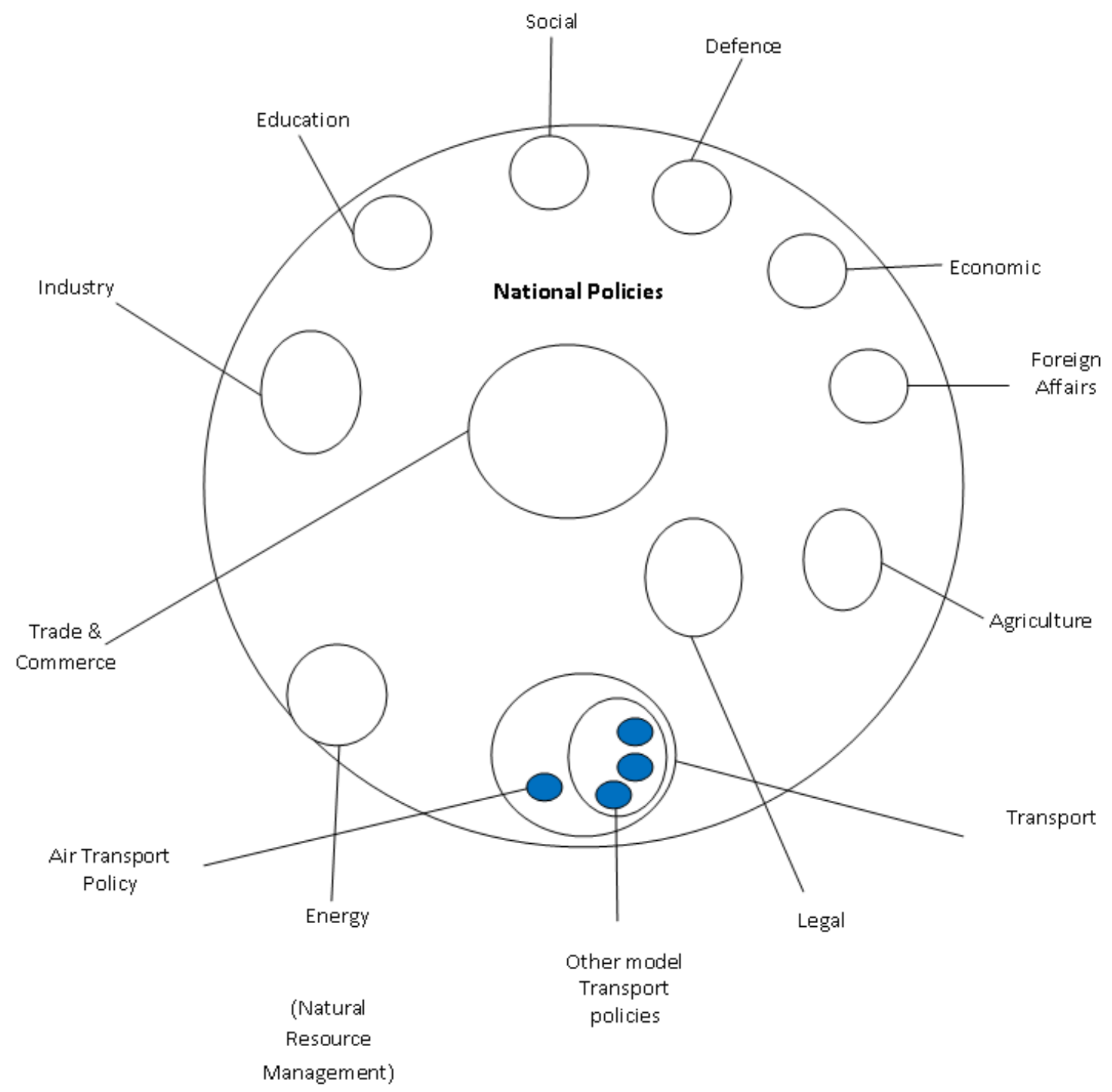

Source: LEAPP (2001)

In the developing world, civil aviation is often not a part of the national planning process.

Infrastructure maintenance and upgrading, equipment and technology procurement, therefore, suffer from uncoordinated actions and lack or minimal funding. In other cases, the lack of integration between the civil aviation policy and other national policies may result in misleading plans based on copying others' practices for the hope of collecting similar successful output, but the results appear to be different. This is sometimes due to a lack of understanding of the social, 
political, or economic role or potential, for air transport in these countries. This also means that the framework, which may be a national civil aviation master plan, must be tied back to national policy, so that a mechanism may be established to ensure that investment continues to be employed most effectively in the future. The same framework must also then be applied to direct and focus potential private sector investors towards projects that are in the national interest (rather than merely in the interests of the investors), and to direct foreign assistance grants, loans and equipment procurement in the same manner.

This paper reviews all possibilities of civil aviation strategy scenarios that are based on conventional pillars of civil aviation strategies. Data Envelopment Analysis (DEA) - a performance benchmarking tool, is used on a sample of 52 countries of different economic stages of development. The objective is to identify the countries which are best using their operating environment indicators to produce the finest possible output from the aviation sector. The analysis also examines the strategies adopted by the "best performers" in an attempt to identify best-in-class civil aviation strategy scenarios which best-fit a specific national macroenvironment.

\section{COMPONENTS OF CIVIL AVIATION STRATEGIC PLAN}

There is no standardized approach to civil aviation planning on national level. However there are some common defined objectives and principle inputs which guide air transport policy. These constitute of a clear set of government agreed objectives for developing the national air transport sector.

Basic approaches to aviation systems planning have emerged from the major agencies funding civil aviation in the developing world. These are the approaches taken by: International and Regional Development Banks, National Development Aid Agencies (Bilateral Aid), and the International Civil Aviation Organization (ICAO). These approaches differ significantly in some cases in purpose, scope and effectiveness. What is worth mentioning is that ICAO was the only agency that managed to develop the concept of the National Civil Aviation Development Plan (NCADP), which formalized the process of aviation systems planning at the national level (Craig, 1989)2. This came about as a result of a growing need to ensure that ICAO's own technical assistance program to civil aviation in the developing countries was managed and implemented so that investment was properly directed. The ICAO approach to creating the 
NCADP involves developing inter-linked national plans for the primary elements of civil aviation - Air Transport, Airspace, Airports and Administration. The process commences at the point of creating or confirming a national air transport policy of the country to which the planning process is being applied. This is fundamental since policy formulation for future air transport services is a primary step in the preparation of the civil aviation plan. Since we are discussing the components of the civil aviation strategic plan, therefore it becomes necessary to identify and describe the inputs that define the national air transport plan.

The national air transport plan provides a long range strategy to develop air transport linkages both within a country and internationally. This plan is the basis for national civil aviation development, since all of the other elements of civil aviation are carried out in support, and for the benefit, of air transport. To a large degree the plan concerns definition of national policy towards air transport to enable this industry to develop nationally, as well as internationally. This generally include principle policy inputs addressing the following three areas: (a) governance through institutional and structural definitions of the legal framework for civil aviation administration; (b) liberalisation of air services through policies determining the government approach towards market access, international air service agreements and prospects for new markets; (c) privatization policies defining the government attitude towards private sector participation in the investment, management or ownership of aviation infrastructure mainly airports and airlines. In terms of privatization policies, this paper focuses on discussing the government policy towards airports' privatization. This is because airline privatization has started much earlier than airports with the deregulation policies in USA in 1978, while airports have historically been considered an essential component of the national aviation system and

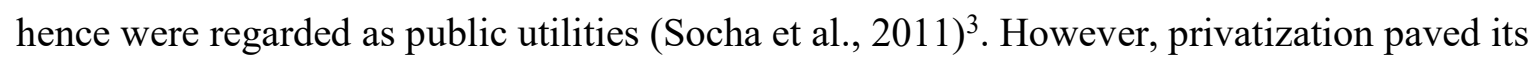
way to airports through the growing pressure to secure financing of airport infrastructure and to encourage more efficient and commercial operations. The first airport privatization took place in the UK with the sale of British Airports Authority (BAA) shared capital in 1987. Afterwards and starting 1996, airport privatization became popular with many privatization activities in Europe, South America and Asia (Graham, 2009) ${ }^{4}$. 


\subsection{The institutional framework of the civil aviation administration}

The institutional framework of the civil aviation administration defines the mechanism by which the components of the national aviation plan can be coordinated for maximum effectiveness and efficiency. It covers the legal framework for civil aviation operations in the country, the administrative organization, including a Civil Aviation Authority (CAA), and establishes the roles and staffing of all of the functional areas of civil aviation administration and regulation, such as Air Traffic Services, Aerodromes, Telecommunications, Flight Operations \& Licensing, Airworthiness, and Air Transport. Also covered by this component are policies for restructuring, such as through the establishment of an autonomous civil aviation authority to regulate the industry's aspects of safety, security, environment in addition to planning for the management of airspace. Restructuring in most cases also leads to the creation of commerciallyindependent Airport Authorities for larger airports, where appropriate, or for regional airport authorities where the combination of smaller airports into commercial units is appropriate. The institutional framework plays an important role in the national aviation sector growth and development as this framework has direct impact on the industry's output and performance. In this regard, ICAO calls governments and departments responsible for civil aviation for an appropriate institutional framework of the civil aviation system, i.e. "the establishment of a civil aviation authority (CAA) and/or other relevant authorities or government agencies, headed by a Chief Executive Officer, supported by the appropriate and adequate technical and non-technical staff and provided with adequate financial resources" (ICAO, 2006) $)^{5}$.

\subsection{Liberalisation of air services}

International air transport operates within the framework of the 1944 Chicago Convention on international air transportation, under which airlines' commercial rights on international routes are governed by a complex web of bilateral air services agreements (ASAs) between each country-pair. These ASAs regulate a wide range of conditions related to the provision of international air services. The World Trade Organization (WTO) Secretariat (WTO 2006) ${ }^{6}$ identified seven features of ASAs as relevant indicators of openness for scheduled air passenger services: (1) Grant of rights 
(air freedoms allowing airlines to provide services over designated markets) ${ }^{\mathrm{a}}$; (2) Capacity clause (regulation on volume of traffic, frequency of service, and/or aircraft types); (3) Tariff approval (whether fares need to be approved before applied); (4) Withholding (which defines the conditions for a foreign carrier to operate, such as ownership and effective citizen control requirements); (5) Designation (which governs the number of airlines allowed to serve the market between two countries and on specific routes); (6) Statistics (which requires the exchange of operational statistics between countries or their airlines); and (7) Cooperative arrangements (which regulate the cooperative marketing agreements between airlines).

The emergence of the policies of deregulation and liberalization of air transport has affected the manner in which the industry operates. A liberalised, harmonized and economically viable development of air transport, promotes the industry's sustainability. However, for liberalisation to achieve its desired objectives, some safeguard measures must be put in place to ensure fair competition, safety, security, environmental protection, consumer protection and dispute resolution mechanism for effective participation and optimal benefits of all economies involved.

Within the framework of the national aviation policy the government should define its stance towards the liberalization of air services which ranges from a restrictive policy with high constraints on clauses of ASA, to a fully liberal air transport policy based on "open skies" agreements without reciprocity. However, the direction adopted by the government towards supporting liberalization of air services or not, should come in harmony with the broader transport policy of other modes of transport, the national economic policy of fostering trade relations, opening up to new markets or promoting tourism $(\mathrm{ICC}, 2005)^{7}$.

\subsection{Airport ownership:}

An important feature of the civil aviation plan is the definition of policy towards participation of the private sector, if any, in the financing, development and operation of

\footnotetext{
a Manual on the Regulation of International Air Transport, or the International Civil Aviation Organization (ICAO) provides the official definition of the freedoms of the air. Available at: http://legacy.icao.int/icao/en/trivia/freedoms_air.htm
} 
infrastructure for the support of civil aviation. Before the 1980s most airports around the world were owned and operated by the public sector. The rising passenger demand due to airlines deregulation in USA led to airports' congestion and the need to invest in additional capacity and to increase the productivity of the existing airports. Therefore, governments headed towards commercialised airport governance by applying businesslike models and allowing market forces, incentives and competition to affect the quality of service. Commercialisation models can incorporate different degrees of private-sector involvement. There exist at least seven possible ownership/governance structures which differentiate between the degree and mode of the shift of airports out of public ownership (Gillen, 2011) $)^{8}$.

- Government owned/operated (US, Spain, Singapore, Finland, Sweden);

- Government owned, privately operated (US “via contracts”, Chile);

- Major airports which have public-private partnerships in the form of Build-OwnOperate (BOO), Build-Operate-Transfer (BOT) and management contract variants (India);

- Independent not-for-profit corporations (Canada);

- Fully private for-profit via IPO (Initial Public Offering) with stock widely held (originally BAA)

- Fully private for-profit via trade sale with share ownership tightly held (Australia, New Zealand);

- Partially private for-profit with private controlling interest (Denmark, Austria, Switzerland); and

- Partially private for-profit with government controlling interest (Hamburg Germany, France, China, Kansai-Japan).

Among these different airport governance/ownership structures, a government should identify through its civil aviation plan the airport governance structure which addresses the aviation sector priorities and assist the government in achieving the desired goals for the civil aviation sector. For example, a government supporting a liberal air transport policy will need to adapt its airport governance/ownership approach to tackle the need for increased capacity, generate more revenues and offer services at a lower cost or promote regional development. 


\section{HYPOTHESIS FOR BEST-IN-CLASS CIVIL AVIATION STRATEGY SCENARIOS}

A common definition for best-in-class would mean that the highest current performance level in an industry is to be used as a standard or benchmark to be equalled or even exceeded. For aviation planning, a best-in-class civil aviation strategy signifies a plan that has consistently shown good results in a specific context. Additionally the results should prove to be superior to those achieved by others while operating under the same conditions. In other words, two or more countries that are pursuing similar policies towards the components of civil aviation strategy, (i.e. aviation administration institutional framework, degree of air service liberalisation and airport ownership model) should be enjoying comparable benefits of aviation. Where this is not the case, then one has to investigate the degree of fitness between the pursued aviation policy on one hand, and the competitiveness level of the surrounding macro-environment factors (political, economic, social, legal and technological) on the other hand. That is because operating conditions have considerable impacts on the output of air transport sector in a country (Itani et al., 2013) $)^{9}$, since the aviation policy is nested within other national policies directed towards social development, education, industry, defence, foreign affairs and trade relations, etc. (Craig, 2001) $)^{10}$. From here rises the necessity to realize the significance of best-in-class civil aviation strategy scenarios.

Based on the three pillars that this paper considers the main components of civil aviation strategy (i.e. aviation administration institutional framework, degree of air service liberalisation and airport ownership model); eighteen theoretical civil aviation strategy scenarios are derived to form options for civil aviation policies for governments to follow (Table 1). Each scenario represents an exclusive combination of three civil aviation strategy pillars. The scenarios are assigned numbers ranging from 18 being the most liberal policy scenario, to 1 being the most restricted policy scenario. 
Table 1: 18 theoretical civil aviation strategy scenarios

\begin{tabular}{|c|c|c|c|}
\hline $\begin{array}{l}\text { Scenario } \\
\text { Number }\end{array}$ & $\begin{array}{l}\text { Availability of } \\
\text { civil aviation } \\
\text { autonomous } \\
\text { regulator }\end{array}$ & $\begin{array}{l}\text { Degree of air } \\
\text { service } \\
\text { liberalisation }\end{array}$ & $\begin{array}{c}\text { Airport } \\
\text { governance/ } \\
\text { ownership model }\end{array}$ \\
\hline 18 & Yes & Full & PSP in ownership \\
\hline 17 & Yes & Full & PSP in management \\
\hline 16 & Yes & Full & No PSP \\
\hline 15 & Yes & Semi & PSP in ownership \\
\hline 14 & Yes & Semi & PSP in management \\
\hline 13 & Yes & Semi & No PSP \\
\hline 12 & Yes & Restricted & PSP in ownership \\
\hline 11 & Yes & Restricted & PSP in management \\
\hline 10 & Yes & Restricted & No PSP \\
\hline 9 & No & Full & PSP in ownership \\
\hline 8 & No & Full & PSP in management \\
\hline 7 & No & Full & No PSP \\
\hline 6 & No & Semi & PSP in ownership \\
\hline 5 & No & Semi & PSP in management \\
\hline 4 & No & Semi & No PSP \\
\hline 3 & No & Restricted & PSP in ownership \\
\hline 2 & No & Restricted & PSP in management \\
\hline 1 & No & Restricted & No PSP \\
\hline
\end{tabular}

Concerning the institutional framework, the availability of autonomous regulator indicates that an appropriate institutional framework for civil aviation administration is in place where the roles, responsibilities and interaction of the aviation industry institutions (policy maker/ regulator/ service providers) are set by well defined laws and regulations. The result is an empowered and adequately funded civil aviation authority. While in the opposite case, where the structure, organization and funding schemes are not well developed; the civil aviation administration is found incapable of taking full benefit of their aviation systems and other assistance programs $(\mathrm{ECAC}, 2007)^{11}$. Countries which suffer from a distorted civil aviation 
institutional framework tend to lack the ability to prevent conflicts arising from regulating the industry and providing aerodrome and air navigation services simultaneously. For the second aviation strategy component which is the degree of air service liberalisation, it is based on the level of openness of ASA clauses. A "full” liberal air transport policy refers to lifting all restrictions on granting foreign operators air traffic rights including no limitations on capacity, tariffs and designation. While a "semi" liberal policy applies to countries pursing a more conservative approach towards variants of the key market access features of ASA's. Such countries, for example, grant $5^{\text {th }}$ or $6^{\text {th }}$ freedom traffic rights, capacity, designation and tariffs options on case by case bases. As for countries following a "restricted" air transport policy, they negotiate and place constraints on features of bilateral ASA'S. In this case traffic rights do not exceed $4^{\text {th }}$ freedom, with restrictions on capacity, tariffs and designation clauses. Finally, for the airport governance/ ownership model it is explained through the definition of policy towards private sector participation (PSP) in the ownership of airports, management of airports or simply a policy prohibiting any form of private sector participation whether in development, operation or ownership of infrastructure for the support of civil aviation.

The 18 proposed scenarios are theoretical in nature and a more realistic approach should be taken in order to explore the best-fit aviation strategy scenario. A questionnaire was distributed to civil aviation departments of 113 countries $^{\mathrm{b}}$ to collect data on the application of the proposed 18 scenarios worldwide. Questions targeted the status of institutional framework of the civil aviation administration; the policy that the country is pursuing towards the liberalisation of air services; and the model of airport ownership (Appendix A). The response rate was $40 \%$ through replies received from 46 civil aviation departments. The data about the remaining countries was collected through industry reports, specifically ICAO database on commercialisation and economic oversight, World Trade Organisation (WTO) air service agreement projector database and related civil aviation administrations' official web pages. A preliminary overview of the

\footnotetext{
${ }^{\mathrm{b}}$ Countries included in the sample are the following: Albania, Algeria, Argentina , Armenia , Australia , Austria , Azerbaijan, Bahrain , Barbados, Belgium, Bolivia, Botswana, Brazil , Brunei , Bulgaria , Burundi , Cameron , Canada, Chile, China, Colombia , Costa Rica, Croatia, Cyprus , Czech Rep., Ecuador, Denmark, Dominican Rep., Egypt , Estonia , Ethiopia , Finland, France, Georgia , Germany, Greece , Guatemala , Honduras , Hong Kong, Hungary, Indonesia , Iceland, India , Iran , Ireland, Italy , Jamaica , Japan , Jordan , Kenya , Korea , KSA, Kuwait, Kyrgyz Rep. , Latvia, Lebanon, Lithuania , Luxembourg, Macedonia , Madagascar , Malaysia , Mali , Malawi, Malta , Mauritania, Mexico, Mongolia, Morocco, Mozambique, Namibia, Netherlands, New Zealand , Nicaragua , Nigeria , Norway, Pakistan, Panama, Paraguay, Peru, Philippines, Poland, Portugal, Oman , Qatar, Romania, Russia, El Salvador, Senegal, Serbia, Singapore, Slovak Rep., Slovenia, South Africa, Spain , Sri Lanka, Sweden, Switzerland, Syria ,Tanzania , Thailand, Trinidad \&Tobago ,Tunisia, Turkey, UAE , Ukraine, Uganda, Uruguay, UK, USA, Venezuela, Vietnam, Zambia, Zimbabwe.
} 
data, as depicted in Figure 2, shows that there exist four scenarios which are not applicable in reality and that no country has adopted such an approach towards its aviation systems planning. This is because these scenarios - namely scenarios number 2, 3, 9 and 12; consist of contradicting approaches toward aviation strategy pillars. For example scenario 3 suggests that a country's civil aviation administration has no independency in regulating the air transport industry, and is pursuing a restricted policy towards liberalisation of air services. However this same country allows private sector ownership in air transport infrastructure which is originally owned by the government under such non-liberal operating conditions. The described situation is far from practical since the under developed capacity of institutions, regulations, oversight capabilities within the civil aviation administration in addition to a lack of coordinated plan towards the growth and development of the national aviation sector, will discourage private investors from acquiring stakes at a government owned aviation infrastructure.

Figure 2: Distribution of world countries over civil aviation strategy scenarios*

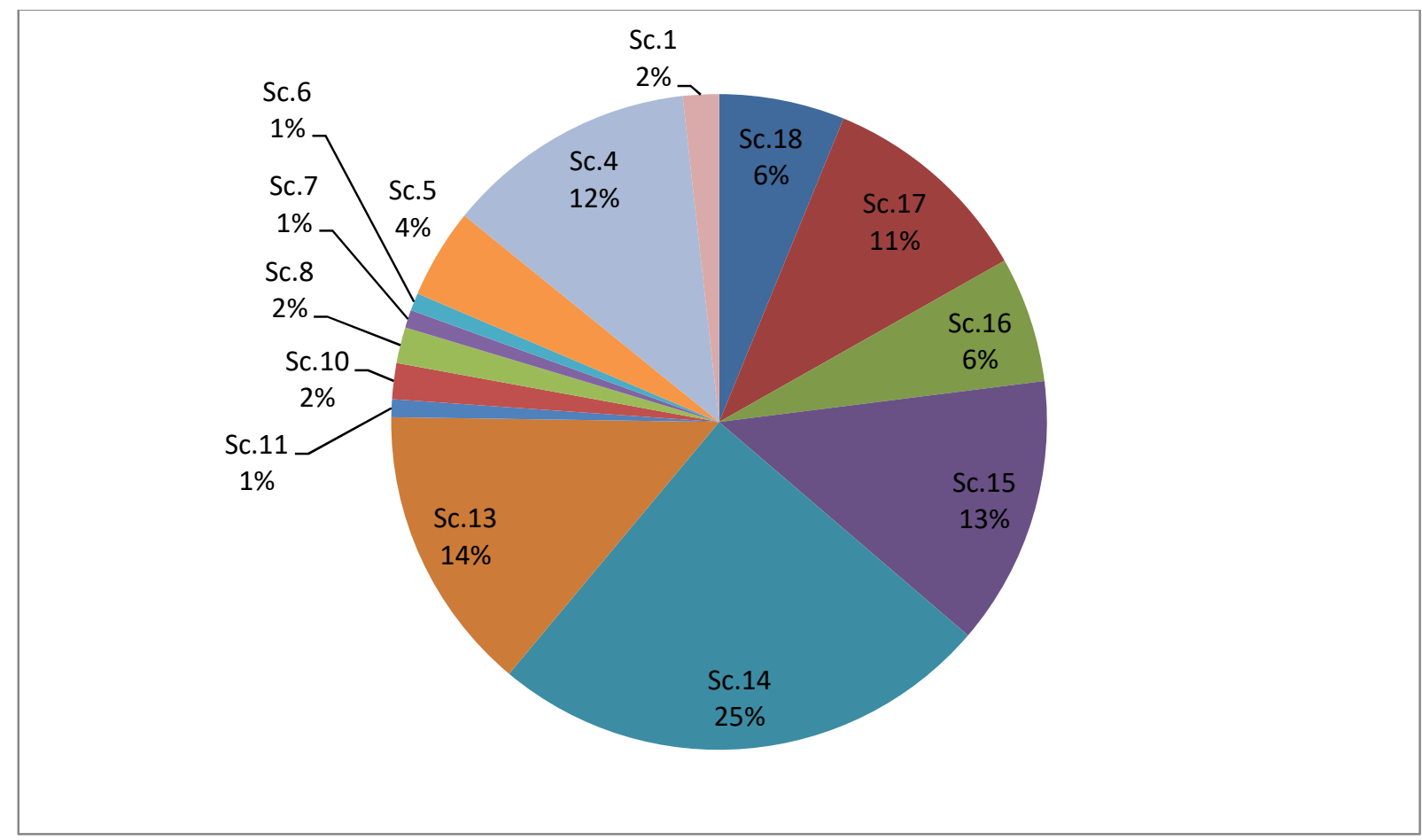

* Distribution is based on countries included in the sample. 
On the other hand, it is found that scenario 14 is the most adopted scenario where 28 countries out of 113 representing $25 \%$ of the sample are adopting the same definition towards the main civil aviation strategy pillars, i.e. the availability of an autonomous civil aviation regulator, a semi-liberal approach towards the provision of air services and private sector participation on airport management and operation levels.

A best-in-class scenario should also comply with international obligations and conform to the industry's global trends. For this reason another set of theoretical scenarios are disregarded since they comprise approaches counteracting with international recommended practices for the development of civil aviation systems. Precisely scenarios 1 to 9 , which suggest a civil aviation institutional framework with no clear separations between service provision and regulatory functions, should be dropped from the category of best-in-class suggested scenarios. This is because the issues of modernisation and corporatisation go hand in hand with the concept of separation between regulatory/oversight functions and service provision functions. Moreover, there is a tendency to link the separation of functions with an increase in efficiency and in responsiveness to the needs of the aviation sector, and thus to the introduction of a private sector managerial concept or the participation of private initiatives.

This view is advocated by the main international organisation like International Civil Aviation Organisation (ICAO, 2009 ${ }^{12} ; 2006^{13}$ ), World Bank (World Bank, 2010 ${ }^{14}$ ), Organisation for Economic Cooperation and Development (OECD, 2010 ${ }^{15}$ ) and Civil Air Navigation Services Organisation (CANSO, 20116) where all of them affirm that experience shows that civil aviation authorities are more successful when they are more autonomous and able to administer and manage their own budgets. Thus separation will give the civil aviation administration more authority and independence required to fulfil their regulatory obligations effectively. In other words, an aviation strategy advising no reform actions towards adapting its legal framework to international obligations may face critical situations due the regulator's inability to manage the industry effectively and answer the needs of the stakeholders which will ultimately affect the industry's output and hamper its growth. Accordingly, such scenarios are not classified under best-in-class aviation strategy scenarios.

The suggested best-in-class aviation strategy scenarios are further decreased by cutting out the ones that do not promote air service liberalisation, namely scenarios 1, 2, 3, 10, 11, 12. Developments in air service liberalisation has proved that increased access to the international 
market for air service providers is a key component for allowing the air transport sector to maximize its contribution to the global economy. Liberalization, particularly as it is exemplified in open-skies agreements, brings with it the economic benefits generated by a more competitive market place, promoting increased travel and trade, enhancing productivity and economic growth. ICAO has already developed and approved recommendations at the Fifth Worldwide Air Transport Conference in 2003 for countries to open up their markets. The number of liberalizing agreements that ICAO Member States have concluded bilaterally, regionally and plurilaterally/multilaterally over the past decade demonstrates a clear international consensus on liberalization's benefits. In 2003 there were 87 liberalized agreements involving 70 countries, while in 2012 there were over 400 liberalized agreements involving 145 states (ICAO, 2013 ${ }^{17}$ ). In addition, the number of liberalizing regional agreements has expanded since 2003; for example, Association of Southeast Asian Nations (ASEAN) members have concluded an agreement to achieve a single open-sky market by 2015 , and other liberal agreements have been concluded by South Pacific Island States, the Caribbean Community and members of the Latin American Civil Aviation Commission (LACAC) ${ }^{18}$. Prior to that in 2008, IATA launched an "Agenda for Freedom" initiative, aimed at facilitating regulatory liberalization. This initiative led to the signing by 12 governments and endorsement of the European Commission of a "Declaration of Policy Principles", which included inter-alia a political commitment to full market access liberalization (IATA, 2013 ${ }^{19}$ ).

Figure 3: Filtering civil aviation strategy scenarios 


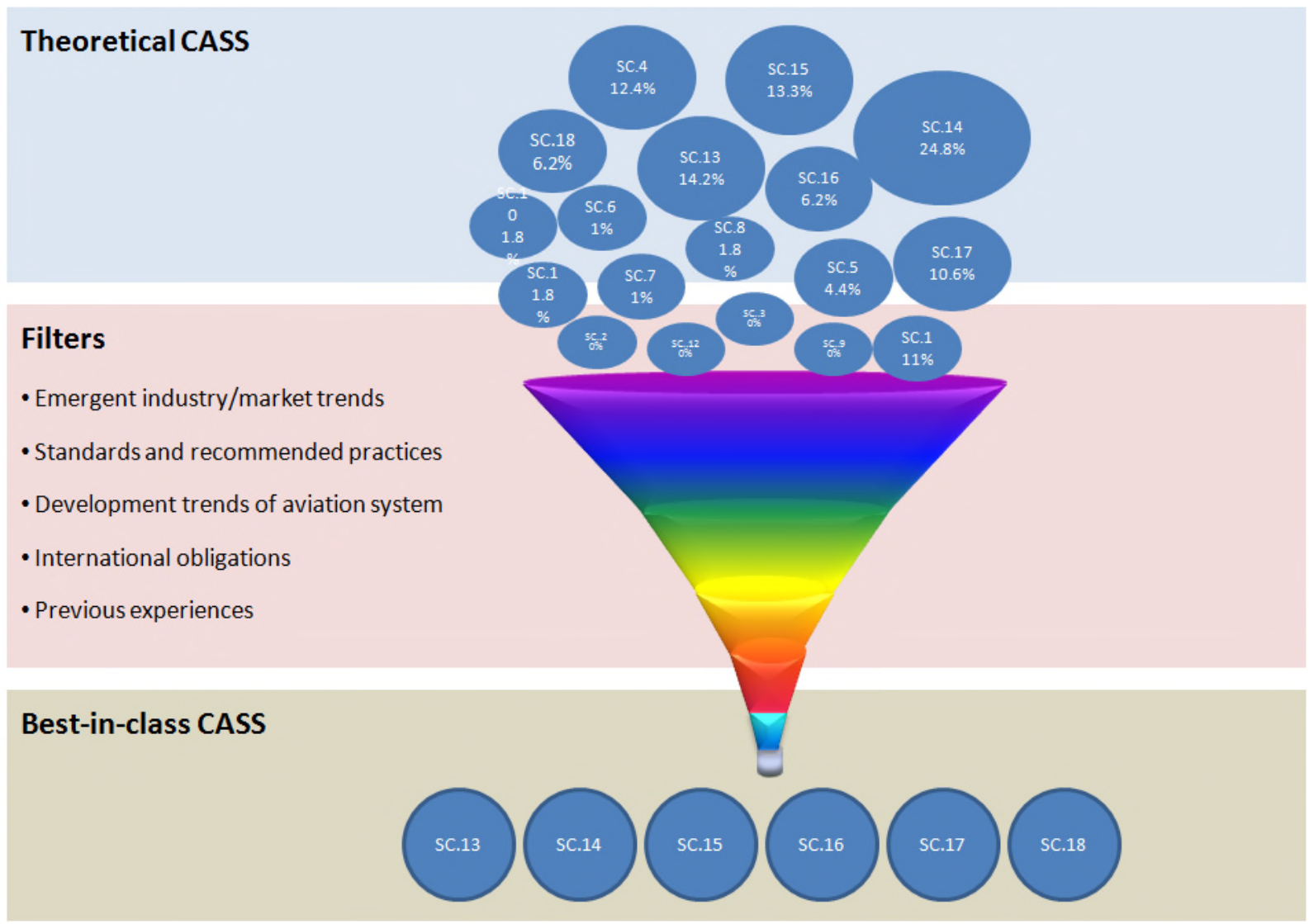

To sum up, international obligations, standards and recommended practices, previous experiences, development trends in aviation systems and emergent industry/market opportunities all serve as filters for realising what we refer to as "best-in-class" civil aviation strategy scenarios (Figure 3). Eliminating the scenarios which do not conform to international approaches for the development of air transport industry's institutional and regulatory frameworks; result in 6 aviation strategy scenarios namely scenarios 13 to 18 . Within a specific macro-environment setting, each of the mentioned dexterous scenarios is able to produce a favourable output of aviation sector in a said country. However, the choice among six best-inclass scenarios remains a national decision which a country has to make in order to seize the highest benefits of its aviation sector taking into consideration the level of maturity of its air transport sector and its operating environment.

\section{PERFORMANCE BENCHMARKING THROUGH USING DATA ENVELOPMENT} ANALYSIS (DEA) 
To ensure effectiveness, best-fit civil aviation strategies should serve as resource optimization tools to align resources to serve air transport priority objectives; such as ensuring connectivity and promoting social and economic welfare of nations. Best-in-class civil aviation strategy scenarios demonstrate the link between resource requirements and industry performance. Such scenarios develop the roadmap to best-use the available resources and upgrade the scarce ones that are needed to bridge performance gaps and improve industry outputs. Hence it becomes relevant to use an efficiency estimation technique to identify the countries which are able to produce the maximum level of air transport industry output with given available macroenvironment input resources. This section discusses the theoretical assumptions of the Data Envelopment Analysis (DEA) method used for estimating air transport sector efficiency on national level through measuring the maximum potential output for a given set of inputs through application on country-level data of 52 countries here referred to as Decision Making Units (DMUs).

\subsection{DEA in literature}

DEA is a relatively new 'data oriented' approach that estimates the maximum potential output for a given set of inputs, and has primarily been used in the estimation of efficiency. It helps to evaluate the performance of a set of peer entities (the DMUs) that convert multiple inputs into multiple outputs. The method of DEA was first introduced by Charnes, Cooper and Rhodes $\left(1978^{20}\right)$ in 1978 while evaluating the efficiency of educational programmes for disadvantaged students. DEA has grown into a powerful tool for evaluating the productivity of sophisticated technological operations. As pointed out in Cooper et al. (2006) $)^{21}$, recent years have seen a widespread application of DEA in evaluating the productivity of the technological processes across a variety of industry sectors. The transport sector research was first to bring in DEA into public passenger transport (Kerstens 199622; Pina, Torres 200123; Boame 200424) and railways (Coelli, Perelman 199925). Ross and Droge (2004) ${ }^{26}$ employed DEA for evaluating the productivity of distribution systems.

Generally, a range of DEA models have been developed by different scholars to measure efficiency and capacity in different ways. These largely fall into two categories of being either input-oriented or output-oriented models. 
With input-oriented DEA, the linear programming model is configured so as to determine how much the input use of a firm could contract if used efficiently in order to achieve the same output level. For the measurement of capacity, the only variables used in the analysis are the fixed factors of production. As these cannot be reduced, the input-oriented DEA approach is less relevant to our case in the estimation of capacity utilization. Modifications to the traditional input-oriented DEA model, however, could be done such that it would be possible to determine the reduction in the levels of the variable inputs conditional on fixed outputs and a desired output level. In contrast, with output-oriented DEA, the linear programme is configured to determine the DMU potential output given its inputs if it operated efficiently as others along the best practice frontier. The choice of input- or output-oriented models depends upon the output realization process characterizing the industry (i.e. minimize the use of inputs to produce a given level of output or maximize the level of output given levels of the inputs). For the purpose of estimating capacity of national air transport output, only the output-oriented DEA measures have been empirically estimated. Output-oriented models are “...very much in the spirit of neoclassical production functions defined as the maximum achievable output given input quantities" (Färe, Grosskopf and Lovell, 199427).

A key advantage of DEA over other examined approaches like Stochastic Production Frontiers $(\mathrm{SPF})^{\mathrm{c}}$ is that DEA more easily accommodates both multiple inputs and multiple outputs.

Additionally, DEA surpasses SPF by being able to indicate the maximum expected output for a given set of variable inputs or factors of production. As a result, it is particularly useful for analysis of multiple inputs of a diversified nature, because prior aggregation of the outputs is not necessary. The DEA technique was applied to the air transport sector in the late 1990's. Such practice was developed by Gillen and Lall (199728, 2001 29 ), Murillo-Melchor (1999) $)^{30}$ and Salazar de la Cruz (1999) $)^{31}$. Tongzon $(2001)^{32}$, Itoh (2002) $)^{33}$, Turner et al. (2004) ${ }^{34}$, Jaržemskienè (2012) $)^{35}$ used DEA for evaluating the productivity of airports. Scheraga $(2004)^{36}$, Capobianco and Fernandes (2004) $)^{37}$ applied DEA for measuring the productivity of air operators. The examples involving the application of DEA methods can also be observed in Abbott and $\mathrm{Wu}(2002)^{38}$, Adler and Berechman $(2001)^{39}$, Bazargan and Vasigh $(2003)^{40}$,

\footnotetext{
${ }^{\mathrm{c}}$ Stochastic Production Frontiers (SPF) is an efficiency measurement approach that measures the production function which defines the technological relationship between the level of input and the resulting level of output. For more information on SPF see Schmidt, P. (1986). Frontier production functions. Econometric Review, 4 (2): 329-334.
} 
Fernandes and Pacheco $(2005)^{41}$, Sarkis and Talluri (2004) ${ }^{42}$. However, only a few researchers made attempts to investigate the issue on a larger than the national scale, for example, at European level (Pels et al. 2003) (3) $^{43}$ international level (Oum, Yu 2003 ${ }^{44}, 2004^{45}$ ). It is worth mentioning that no previous attempts has been made to estimate the efficiency of output of the air transport sector at a national level in relation to given macro-environment inputs.

\subsection{DEA application}

For this study, a sample was built including 52 countries (DMUs) of various stages of economic development from different geographical regions (Figure 4). At the early stages of the research, the sample consisted of 113 countries. Afterwards and during the data collection process, 61 countries were excluded due to the unavailability of consistent and credible indices respective to their macro-environment forces. Hence the final result is a sample of 52 countries where sixteen different indicators are collected for each country and distributed between two categories specifically twelve input variables and four output variables.

Figure 4: Countries included in the DEA model*

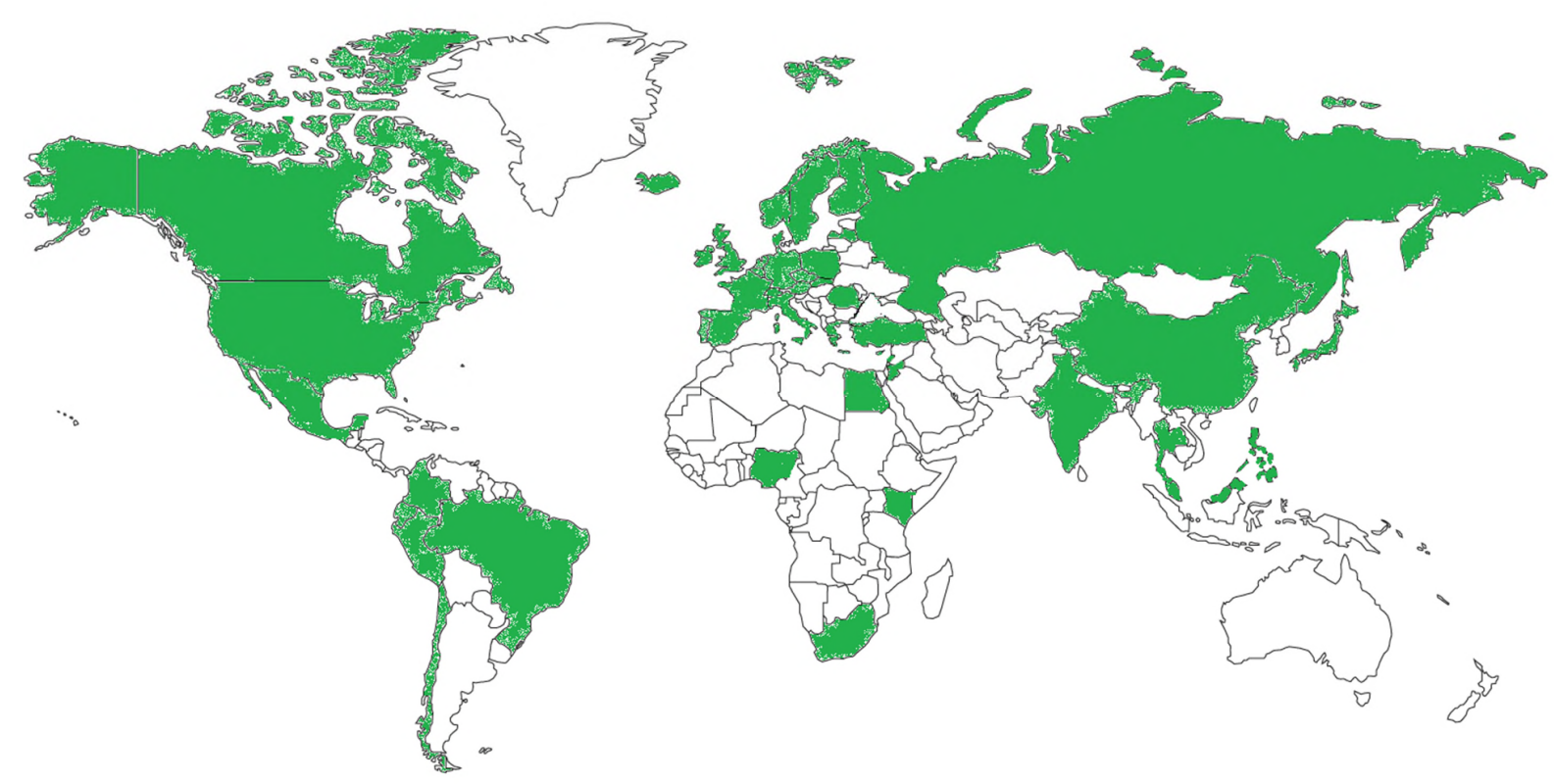


*Americas: Brazil, Canada, Chile, Colombia, Ecuador, Mexico, Peru, USA. Europe: Austria, Belgium, Cyprus, Czech republic, Denmark, Finland, France, Germany, Greece, Hungary, Iceland, Ireland, Italy, Latvia, Luxembourg, Malta, Netherlands, Norway, Poland, Portugal, Romania, Spain, Sweden, Switzerland, UK. Africa: Egypt, Kenya, Nigeria, South Africa. Asia: China, Hong Kong, India, Japan, Jordan, Lebanon, Malaysia, Philippines, Russia, Singapore, Thailand, Turkey, UAE. Oceania: Australia, New Zealand

Input variables include the nine pillars of national competitiveness as identified by the World Economic Forum-Global Competitiveness Report (WEF-GCR) ${ }^{46}$. Additional three input variables of macro-environment nature and of a significant impact on air transport productivity are included which are: travel and tourism competitiveness, the level of political and security stability and country surface area in Sq Km. As for the air transport industry output, we restricted the analysis to four indicators due to the unavailability of reliable data on other outputs and limitations concerning the countries included in the sample. The four output variables used in the analysis are: total passengers per country, total contribution of air transport to national GDP, total contribution of air transport to employment and the level of connectivity of a specific country through using the Air Connectivity Index (ACI). For the sake of consistency, the data reported on all the mentioned variables is for 2009. Table 2 illustrates the used input and output variables with reference to the sources of data.

Table 2: Input and output variable with related data sources

\begin{tabular}{lll}
\hline Input variables & Source \\
1 & Institutions & \\
2 & Infrastructure & \\
3 & Health and primary education & \\
4 & Goods and market efficiency & World economic forum: Global \\
5 & Labor market efficiency & \\
6 & Market size & \\
7 & Innovation & \\
8 & Higher education and training & \\
9 & Macro-economic environment &
\end{tabular}


10 Travel and tourism competitiveness

11 Political and security stability

12 Country surface area in Sq Km
World economic forum: Travel \& tourism competitiveness report $(2009)^{47}$

Institute of economics and peace: Global peace index $(2009)^{48}$

United Nations (2013) 49

\section{Output variables \\ Source \\ 1 Total aviation contribution to GDP \\ Oxford economics: Economic benefits \\ 2 Total aviation contribution to employment from air transport-country reports $(2011)^{50}$ \\ 3 Total passengers \\ ICAO data: total schedules passengers $(2009)^{51}$ \\ 4 Air Connectivity Index (ACI) \\ World Bank (2011) $)^{52}$}

In DEA, the envelopment surface will differ depending on the scale assumptions that underpin the model. Two scale assumptions are generally employed: constant returns to scale (CRS), and variable returns to scale (VRS). The latter encompasses both increasing and decreasing returns to scale. CRS reflects the fact that output will change by the same proportion as inputs are changed (e.g. a doubling of all inputs will double output); VRS reflects the fact that input indicators may exhibit increasing, constant and decreasing returns to scale.

The analysis was undertaken using the program "DEA Solver Pro. 9.0". For the purpose of the estimation of capacity utilization, each country-level air transport observed output is assumed to occur in the same time period in 2009. A summary of DEA results in terms of number of efficient countries, average Capacity Utilisation (CU) scores over all the sample units, with standard deviation, maximum and minimum values of scores are presented in Table 3 . The CU scores range from zero to 1 , with 1 being efficient full capacity utilization (i.e. 100 percent of capacity). Values less than 1 indicate that the country is operating at less than full capacity given the set of fixed inputs (inefficient).

The DEA output oriented model resulted in twenty-three countries with technically efficient capacity utilization. Seven of which are efficient under CRS and the other sixteen countries are found using efficiently their input to produce optimal capacity output under VRS. These 
countries form the set of efficient frontier representing the best practice of the sector (benchmark). It is worth mentioning that USA and UAE showed the highest two operational frequency of 29 and 19 respectively. That means USA and UAE capacity utilization models are being used the most as a benchmark reference by other inefficient DMUs in an attempt to produce efficient output.

Table 3: Summary of results of output oriented DEA model

\begin{tabular}{lrr}
\hline Measures & CRS-O & VRS-O \\
\hline Number of efficient units & 7 & 16 \\
Average Scores & 0.676 & 0.700 \\
SD & 0.289 & 0.325 \\
Maximum & 1.0 & 1.0 \\
Minimum & 0.149 & 0.156 \\
\hline
\end{tabular}

Estimates of capacity utilization are obtained assuming both constant and variable returns to scale. As would be expected, the CRS analysis resulted in lower estimates of capacity utilization and greater estimates of capacity output than the VRS analysis. Further, when VRS were assumed, most countries were found to reflect utilisation at full capacity (Table 4).

Table 4: Capacity utilisation and technically efficient capacity output 


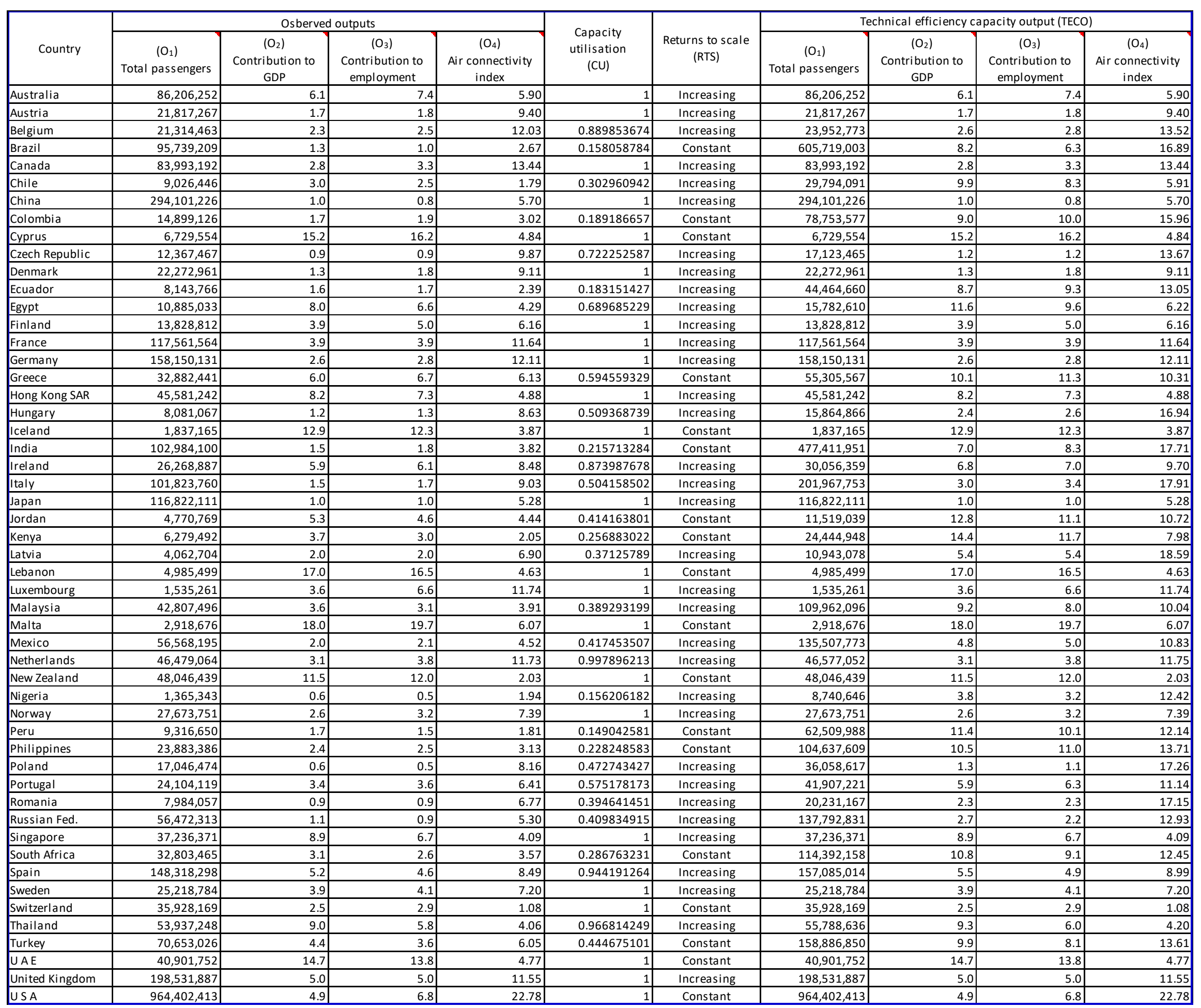


A number of observations can be made on the model results. First, DEA helps in identifying the performance level of individual countries, as well as the overall efficiency of the whole sample. The overall average of output oriented relative performance (based on variable return to scale assumption, VRS-O) of all countries is $70 \%$, meaning that on average the countries included in the sample can produce $30 \%$ more output given the same level of input. On the other hand, out of 52 countries, twenty three are using their inputs efficiently to produce maximum capacity output $(100 \%)$. This means that the majority (29 countries) are performing inefficiently and therefore need to look into ways to maximize their outputs. The overall average of capacity utilization by inefficient performance countries is $47 \%$, implying that all of which are performing at less than $50 \%$ capacity. However, much of this underutilization of capacity arose out of using the inputs inefficiently rather than not using enough variable inputs. If the inputs had been used efficiently, then the capacity utilization for the underperforming countries would have been greater.

Additionally, the performance scores of the whole sample vary between 14\%-100\% implying that least performing counties like (Peru, Nigeria and Brazil) can learn from other peer efficient countries and utilize their given input efficiently to maximize the benefits of the air transport sector by producing up to $86 \%$ more capacity output. Further, the country level information provides guidance as to which countries exploiting their factors of national competitiveness may be in most need of capacity management measures. Such discrimination between the best performers and the under performers could guide policy makers and regulators on drafting strategies and plans. This will ensure full coordination and contribution of the country's national factors of competitiveness into producing an optimal air transport sector output which is represented here by number of passengers, aviation contribution to GDP and aviation contribution to employment.

Although the examined countries are of different stages of development, it is evident that all the output efficient countries are efficiency and innovation driven economies. That means those countries are more dependent on efficiency and innovation enhancers rather than on their factor endowments to improve their competitiveness. ${ }^{4}$ In other words, countries in a more advanced

\footnotetext{
${ }^{4}$ In line with the economic theory of stages of development, economies in the first stage are mainly factor-driven and compete based on their factor endowments - primarily low-skilled labour and natural resources. As a country becomes more competitive, productivity will increase and wages will rise with advancing development. Countries will then move into the efficiency-driven stage of development. Finally, as countries move into the innovationdriven stage, higher wages and the associated standard of living will be sustained through businesses which compete by producing new and unique goods, services, systems, processes through new technologies and/or the most sophisticated production processes or business models. For more info on theory of stages of development see:
} 
stage of development tend to utilise given factors of national competitiveness in a more efficient way to maximize air transport output. At the input level, $65 \%$ of efficiently performing countries are utilizing their political and security stability factor to maximize output compared to $52 \%$ of inefficient performing countries. As for the market size factor, $62 \%$ of underperforming countries tend to rely on this factor in comparison to $26 \%$ of maximum capacity performing countries. This indicates that efficient countries utilise given inputs in a different manner than inefficient ones. Even the weight distribution among different factors of national competitiveness shows a dissimilarity of dependency to maximize capacity output between well performing and underperforming DMUs. Countries which need to make improvements to their capacity outputs (i.e. inefficient DMUs) are depending mainly on inputs such as education system, goods market and market size. Contrary to the best performing industry benchmarks (i.e. efficient DMUs) which are depending on factors such as institutions, infrastructure, health system, labor market efficiency, business innovation and travel and tourism competitiveness to produce maximum capacity output of air transport system (Figure 5). However, both efficient and inefficient DMUs are relying on two common factors which are economic environment and political and security stability to achieve maximum capacity output.

Figure 5: Weight distribution of inputs: efficient vs. inefficient DMUs

Rostow, W.,The Stages of Economic Growth, Cambridge University Press, 1960 and Porter, M., The Competitive Advantage of Nations, Free Press, New York, 1990. 


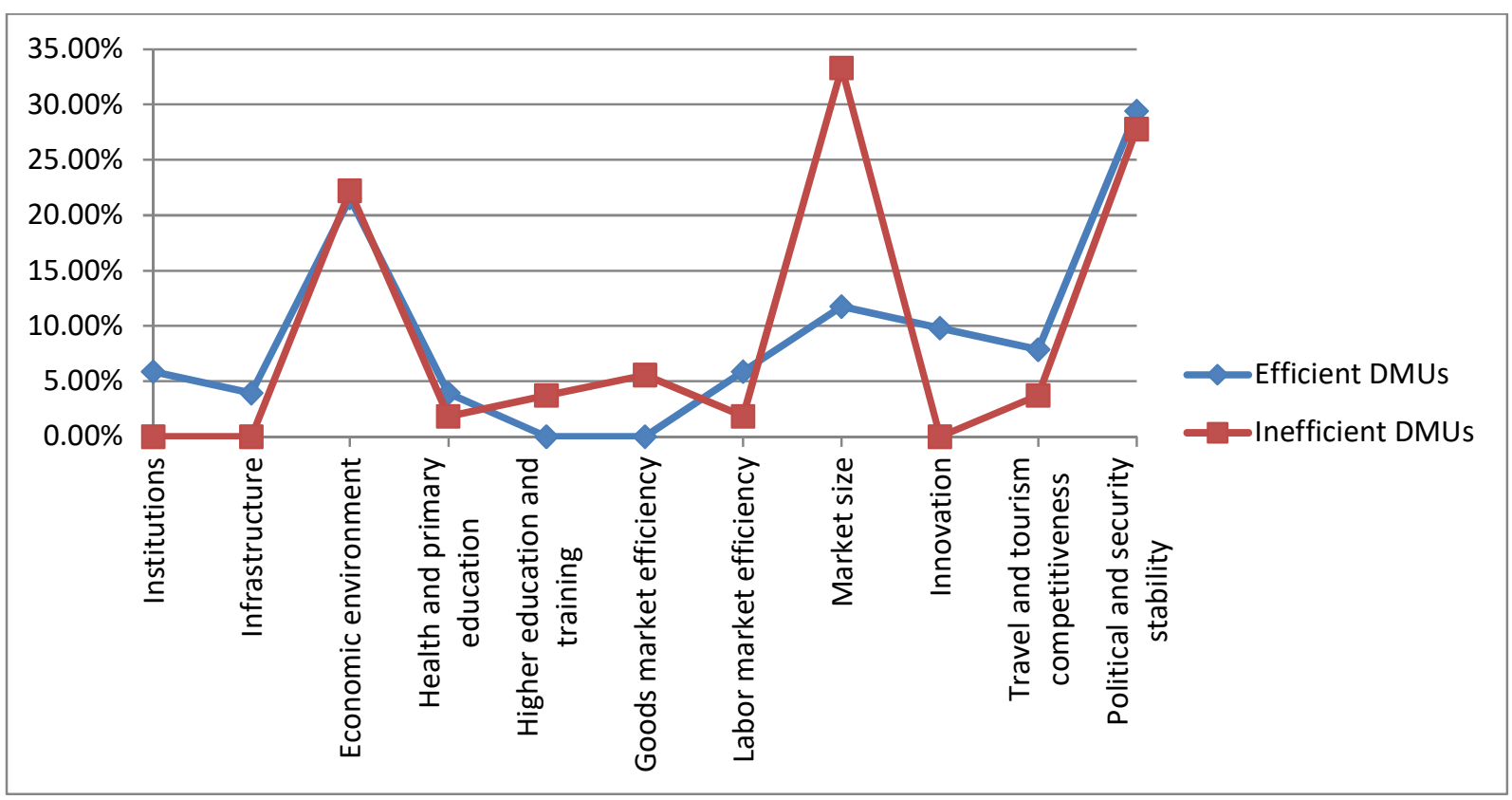

4.3 Civil aviation strategy scenarios and efficient DMUs

In light of the discussed hypothesis of the six best-in-class civil aviation strategy scenarios, this section examines the aviation strategies adopted by the countries which validated an efficient use of input variables to produce maximum capacity output of aviation system. The well performing countries - as per the results of the DEA model, are categorized based on the aviation strategy adopted. Figure 6 provides a visual representation of the distribution of the efficient DMUs over their choice of aviation strategies. It is apparent that all the well-performing countries are following one of the best-in-class aviation strategies. No country of the best performers is adopting a scenario other than the earlier identified best-fit aviation strategies. This validates our hypothesis towards realizing world's best-in-class aviation strategies. In the first part of this paper the identified 6 optimum strategy scenarios were the result of a thorough examination of international obligations, standards and recommended practices, previous experiences, development trends in aviation systems and emergent industry/market opportunities. The beforementioned serve as filters for realising what we refer to as "best-in-class" civil aviation strategy scenarios (Figure 3). Moreover, the results of the DEA output oriented model proved that the identified best-in-class aviation strategies are to be considered industry benchmarks since they are being selected by the worlds' most efficient countries in terms of aviation output capacity production. The identified aviation policy scenarios are aiding the best performing countries in 
reaching full operating capacity given an efficient utilization of their factors of national competitiveness.

Figure 6: Full capacity operating countries and best-in-class aviation strategy scenarios

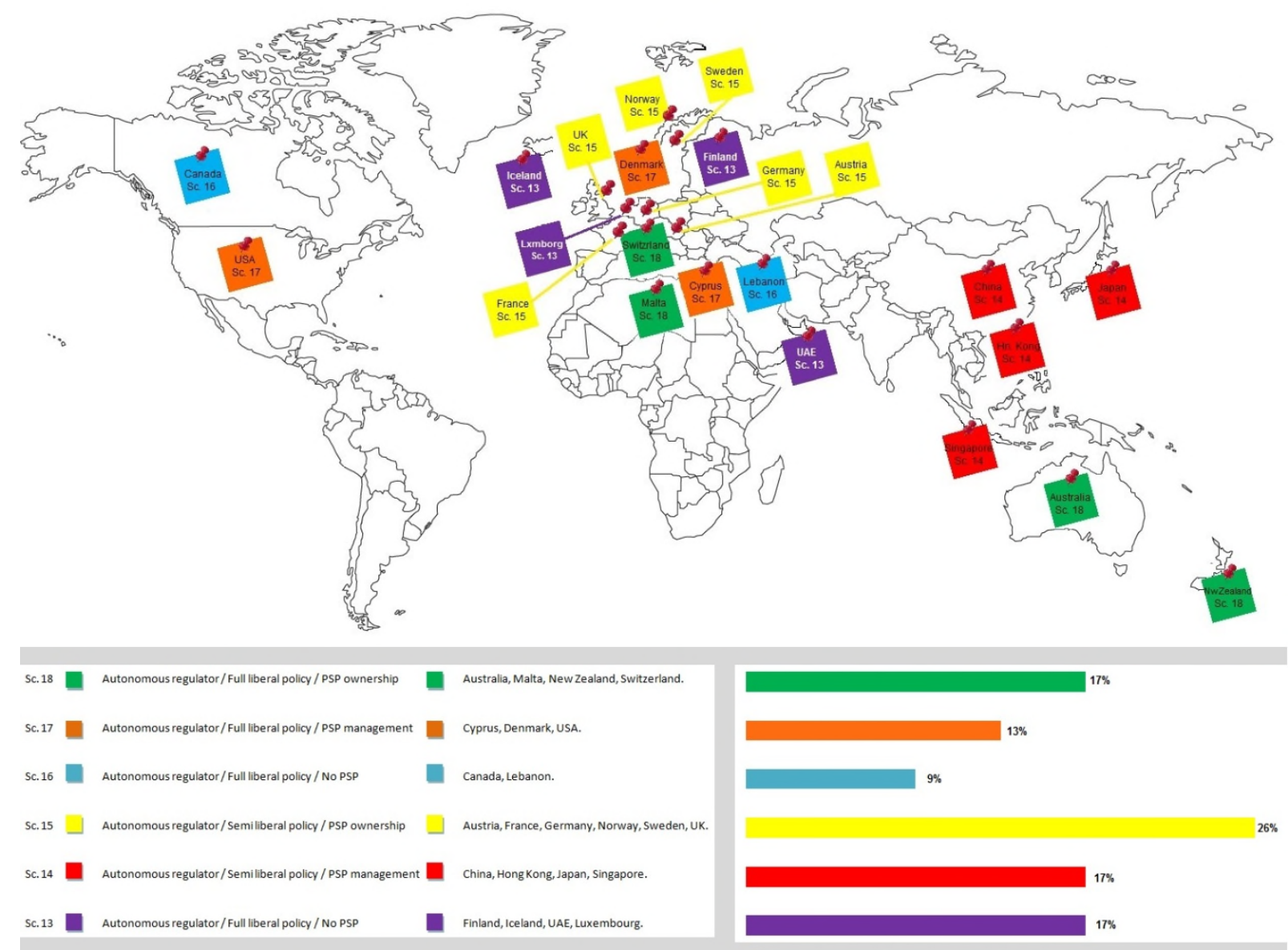


A further examination of the results demonstrates that scenario 15 is the most adopted aviation policy scenario amongst the identified six best-in-class ones. This leads to a result that $26 \%$ of the efficiently performing countries are adopting this aviation policy scenario. Countries following scenario 15 which are: Austria, France, Germany, Norway, Sweden and the United Kingdom are all geographically located in Europe. Those countries have established autonomous civil aviation authority regulators and practice a semi-liberal air transport policy while allowing for private sector participation in the ownership of airports. Contrary to the least adopted aviation policy scenario 16, that is only favoured by two efficient performers namely: Canada in the Americas and Lebanon in the Middle East. It is notable that all the efficient countries identified in East Asia namely: China, Hong Kong, Japan and Singapore have chosen scenario 14 as the preferred aviation policy among others best-in-class strategy scenarios.

\section{CONCLUSION}

There is no standardized valid approach to civil aviation planning on national level. However there are some common defined goals and principle inputs which guide air transport policy towards achieving priority objectives such as ensuring sufficient connectivity and promoting social and economic welfare. However, a best-in-class civil aviation strategy signifies a plan that has consistently shown good results in different contexts.

The present study makes a number of contributions. First, it is the only study to attempt realizing best-in-class civil aviation strategies through establishing a link between the national operating macro-environment and the air transport sector's output efficiency. Second, it has validated the significant relationship among the selected input and output variables through examining them under a comparative analysis approach through using the Data Envelopment Analysis (DEA) model. The study provides both theoretical and empirical evidence for realizing the six best-in-class aviation strategy scenarios. The identified scenarios are the result of a thorough examination of the aviation industry's international obligations, standards and recommended practices, countries' previous experiences, development trends in aviation systems and emergent industry/market opportunities. 
Moreover, the results of the DEA model proves that the realized best-in-class aviation strategies are to be considered industry benchmarks since they are being selected by the worlds' most efficient countries in terms of aviation output capacity production. The identified aviation policy scenarios serve as a resource-optimization tool for efficient utilization of resources. They guide underachieving countries and some nations in the developing world to achieve the best-fit combination between aviation policy and level of national competitiveness. The results call upon aviation policy makers to adopt an efficient peer analysis approach to select the best-fit aviation strategy out of the identified six best-in-class policies for efficient use of available resources to bridge performance gaps and achieve full operating capacity. As a result, governments are more enabled to set the appropriate vision for the future of civil aviation and establish an approach to direct and prioritize investment in their civil aviation sector. 


\section{REFERENCES}

${ }^{1}$ LEAPP (2001), Restructuring of civil aviation administration. Leading Edge Aviation Planning Professionals.

2 "National Civil Aviation Development Plan - Review \& Requirements", Victor F. J. Craig, Civil Aviation Advisor, International Civil Aviation Organization, Technical Assistance Mission to Malawi, September 1989.

${ }^{3}$ Socha, L., Kavka, P., Necas, P., (2011). Airlines privatisation aspects. International conference of scientific papers. Romania, 26-28 May 2011.

${ }^{4}$ Graham, A., (2009). Fundamentals of airport privatization and concession policies.

${ }^{5}$ ICAO Doc 9735, AN/960. Safety oversight audit manual, second edition, 2006. Published by ICAO. Montreal, Canada.

${ }^{6}$ World Trade Organisation (2006), "Second Review of the Air Transport Annex: Developments in the Air

Transport Sector (Part Two) Quantitative Air Services Agreements Review (QUASAR),' 'Volumes I and II Note by the Secretariat, document S/C/W/270/Add.1.

${ }^{7}$ International Chamber of Commerce-ICC (2005). The need for greater liberalisation of international air transport. Document 304-2/23. Revision 3.

${ }^{8}$ David, G., 'The evolution of airport ownership and governance', Journal of Air Transport Management, 17, 12th Hamburg Aviation Conference, pp. 3-13, Science Direct, EBSCO host, viewed 24 April 2013.

${ }^{9}$ Itani, N., O’Connell, J.F., Mason, K. (2013). A macro-environment approach to civil aviation strategic planning. Manuscript submitted for publication.

${ }^{10}$ Craig, V. (2001). Aviation systems planning: an approach for the developing world. Leading Edge Aviation Planning Professionals (LEAPP).

${ }^{11}$ European Civil Aviation Conference-ECAC (2007). Working paper presented on $36^{\text {th }}$ session of ICAO Assembly. Montreal, Canada: 18-28 September 2007.

12 ICAO. Doc 9082. ICAO's Policies on Charges for Airports and Air Navigation Services. 2009

${ }^{13}$ ICAO. Doc. 9562. Airport Economics Manual. 2nd Edition 2006.

${ }^{14}$ World Bank. Investment in Air Transport Infrastructure: Guidance for developing private participation. PPIAF, 2010 .

${ }^{15}$ OECD. Privatisation in the $21^{\text {st }}$ Century: Summary of Recent Experiences. 2010.

${ }^{16}$ CANSO. Guide to Separation of Service Provision \& Regulation. August 2011.

${ }^{17}$ Examination of key issues and regulatory framework: liberalisation of market access. Report issued by the ICAO Secretariat General at the ICAO Worldwide Air Transport Conference (ATCONF), sixth meeting in Montréal, 18 to 22 March 2013. ATConf/6-DP/5.

${ }^{18}$ Examination of key issues and regulatory framework: liberalisation of market access. Working paper presented by USA at the ICAO Worldwide Air Transport Conference (ATCONF), sixth meeting in Montréal, 18 to 22 March 2013. ATConf/6-WP/60.

${ }^{19}$ List of countries that have signed/endorsed the Multilateral Statement of Policy Principles is available at: http://www.agenda-for-freedom.aero/Pages/default.aspx

${ }^{20}$ Charnes, A., W.W. Cooper, and E. Rhodes, 1978, Measuring the efficiency of decision making units, European Journal of Operational Research 2, 429-444.

${ }^{21}$ Cooper W.W, Seiford, L.M.; Tone, K. 2006. Data Envelopment Analysis: A Comprehensive Text with Models, Applications, References and DEA-Solver Software. $2^{\text {nd }}$ edition. Springer, 528p.

${ }^{22}$ Kerstens, K, 1996. Technical efficient measurement and explanation of French urban transit companies, Transportation Research Part A: Policy and Practice 30(6): 341-452. http://dx.doi.org/10.1016/0965-8564(96)00006-7

${ }^{23}$ Pina, V.; Torres, L.2001. Analysis of the efficiency of local government services delivery. An application to urban public transport, Transportation Research Part A: Policy and Practice 35(10):929-944.

http://dx.doi.org/10.1016/S0965-8564(00)00033-1

${ }^{24}$ Boame, A. K. 2004. The technical efficiency of Canadian urban transit systems, Transportation Research Part E: Logistics and Transportation Review 40(5): 401-416. http://dx.doi.org/10.1016/j.tre.2003.09.002

${ }^{25}$ Coelli, T.; Perelman, S. 1999. A comparison of parametric and non-parametric distance functions: with application to European railways, European Journal of Operational Research 117(2): 326-339.

http://dx.doi.org/10.1016/S0377-2217(98)00271-9

${ }^{26}$ Ross, A. D.; Droge, C. 2004. An analysis of operations efficiency in large-scale distribution systems, Journal of Operations Management 21(6):673-688. http://dx.doi.org/10.1016/j.jom.2003.11.003

${ }^{27}$ Färe,R., Grosskopf, S., and Lovell, K. (1994). Production Frontiers, University of Cambridge, New York, USA. 
${ }^{28}$ Gillen, D.; Lall, A. 1997. Developing measures of airport productivityand performance: an application of data envelopment analysis, Transportation Research Part E: Logistics and Transportation Review 33(4): 261-273. http://dx.doi.org/10.1016/S1366-5545(97)00028-8

${ }^{29}$ Gillen, D.; Lall, A. 2001. Non-parametric measures of efficiency of U.S. airports, International Journal of Transport Economics= Rivista Internazionale de Economia dei Trasporti 28(3): 283-306.

${ }^{30}$ Murillo-Melchor, C. 1999. An analysis of technical efficiency and productivity changes in Spanish airports using the Malmquist index, International Journal of Transport Economics=Rivista Internazionale de Economia dei Trasporti 26(2): 271-292.

${ }^{31}$ Salazar de la Cruz, F. 1999. A DEA approach to the airport productivity function, International Journal of Transport Economics = Rivista Internazionale de Economia dei Trasporti 26(2): 255-270.

32 Tongzon, J. 2001. Efficiency measurement of selected Australian and other International ports using data envelopment analysis, Transportation Research Part A: Policy and Practice 35(2): 107-122.

http://dx.doi.org/10.1016/S0965-/8564(99)00049-X

${ }^{33}$ Itoh, H. 2002. Efficiency changes at major container ports in japan: a window application of data envelopment analysis, Review of Urban and Regional Development Studies 14(2):133-152. http://dx.doi.org/10.3846/16484142.2009.24.192-199

${ }^{34}$ Turner, H.; Windle, R.; Dresner, M. 2004. North American container port productivity: 1984-1997, Transportation Research Part E: Logistics and Transportation Review 40(4):339-356. http://dx.doi.org/10.1016/j.tre.2003.06.001

${ }^{35}$ Ilona Jaržemskiene (2012): Applying the method of measuring airport productivity in the Baltic region, Transport, 27:2, 178-186. Available at: http://dx.doi.org/10.3846/16484142.2012.694079

${ }^{36}$ Scheraga, C. A. 2004. Operational efficiency versus financial mobility in the global airline industry: a data envelopment and Tobit analysis, Transportation Reseach Part A: Policy and Practice 38(5): 383-404. http://dx.doi.org/10.1016/j.tra.2003.12.003

${ }^{37}$ Capobianco, H. M. P.; Fernandes, E. 2004. Capital structure in the world airline industry, Transportation Research Part A: Policy and Practice 38 (6).

${ }^{38}$ Abbott, M.; Wu, S. 2002. Total factor productivity and efficiency of Australian airports, Australian Economic Review 35(3): 244-260. http://dx.doi.org/10.1111/1467-8462.00241

${ }^{39}$ Adler, N.; Berechman, J. 2001. Measuring airport quality from the airlines' viewpoint: an application of data envelopment analysis, Transport Policy 8(3): 171-181. http://dx.doi.org/10.1016/S0967-070X(01)00011-7

${ }^{40}$ Bazargan, M.; Vasigh, B. 2003. Size versus efficiency: a case study of US commercial airports, Journal of Air Transport Management 9(3): 187-193. http://dx.doi.org/10.1016/S0969-6997(02)00084-4

${ }^{41}$ Fernandes, E.; Pacheco, R. R. 2005. Impact of changes in management style on the performance of Brazilian airports, in proceedings of the 9th Air Transport Research Society World Conference. Rio de Janeiro, Brazil, 3-7 July 2005, 1-24 [CD].

${ }^{42}$ Sarkis, J.; Talluri, S. 2004. Performance based clustering for benchmarking of US airports, Transportation Research Part A: Policy and Practice 38(5): 329-346. http://dx.doi.org/10.1016/j.tra.2003.11.001

${ }^{43}$ Pels, E.; Nijkamp, P.; Rietveld, P. 2003. Inefficiencies and scale economies of European airport operations, Transportation Research Part E: Logistics and Transportation Review 39(5): 341-361.

http://dx.doi.org/10.1016/S1366-5545(03)00016-4

${ }^{44}$ Oum, T. H.; Yu, C.; Fu, X. 2003. A comparative analysis of productivity performance of the world's major airports: summary report of the ATRS global airport benchmarking research report - 2002, Journal of Air Transport Management 9(5): 285-297. http://dx.doi.org/10.1016/S0969-6997(03)00037-1

${ }^{45}$ Oum, T. H.; Yu, C. 2004. Measuring airports' operating efficiency: a summary of the 2003 ATRS global airport benchmarking report, Transportation Research Part E: Logistics and Transportation Review 40(6): 515-532. http://dx.doi.org/10.1016/j.tre.2004.08.002

${ }^{46}$ WEF (2009), Porter, M. E., Sachs, J. D., Warner, A.M., Cornelius, P. K., Levinson, M., \& Schwab, K., The Global Competitiveness Report 2011. New York: Oxford University Press for World Economic Forum.

${ }^{47}$ WEF (2009), Jennifer Blanke and Thea Chiesa, The Travel and Tourism Competitiveness Report 2009. New

York: Oxford University Press for World Economic Forum.

${ }^{48}$ IEP, 2009. Global Peace Index (GPI). Institute for Economics and Peace, Australia.

${ }^{49}$ United Nations (2013), World statistics pocket book, , United Nations.

${ }^{50}$ Oxford Economics (2009), Benefits of Aviation-Country reports. Oxford, United Kingdom.

${ }^{51}$ ICAODATA (2009). Total scheduled passengers traffic by country, available at: www.icaodata.com.

${ }^{52}$ World Bank (2011). The air connectivity index, WPS5722, World Bank publications. 
2015-05-29

\title{
Towards realizing best-in-class civil aviation strategy scenarios
}

\author{
Itani, Nadine
}

Elsevier

Itani N, O'Connell JF, Mason K. (2022) Towards realizing best-in-class civil aviation strategy scenarios. Transport Policy, Volume 43, October 2015, pp. $42-54$

https://doi.org/10.1016/j.tranpol.2015.05.013

Downloaded from Cranfield Library Services E-Repository 